\title{
POTASSIUM IODIDE AS A PROVOCATION TEST IN LEPROSY
}

\author{
EXPERIENCE OF 244 CASES AT NGOMAHURU LEPROSY \\ HOSPITAL, SOUTHERN RHODESIA
}

\section{B MoIser}

This test has been carried out over a period of 2 years. 209 males and 35 females, total 244 , were subjected to the test. All were patients who had undergone treatment here for several months, and all were in robust health. Most of them were negative to the microscope, but a few who were still slightly positive were included, for comparison. Treatment with Moogrol had already been stopped.

The drug was given once a week, in the following doses:- 5 , Io, $20,40,80,160,240,320$, and 320 grains in a pint or more of water, i.e. the test lasted for 9 weeks in each case.

The patients were not kept in the ward, but were examined daily, and temperatures taken.

It may be noted at once that the patients did not like the test, but only one man refused to go on with it to the end. They complained of abdominal pain, frontal headache, sore throat and a feeling of nausea, and a nasty taste in the mouth after the larger doses, but coryza was markedly absent.

In 196 cases, there was no ill effect whatever. In 25 cases skin reactions only occurred, I after 5 grains, 3 after 10, 6 after 20 , 2 after 40,3 after 80,4 after 160,5 after 240 , and I after 320 grains.

In 4 cases, there was a rise of temperature only, whilst in I9 cases, there were both skin reactions and pyrexia. 3 occurred after 40 grains, 6 after 80,5 after 160, 3 after 240, I after first 320, and I after second dose of 320 grains.

One female patient died suddenly in the afternoon, after receiving 40 grains at mid-day. The cause of death is unknown since post-mortem examinations are strongly objected to. There was no reason to suppose that death was due to K-I.

In case of failure to pass the test, it was repeated at an interval varying from one to three months. 
Thus:-

23 failed at the first test.

6 failed at the first and second test.

2 failed at the first, second and third test.

I 8 passed at the second test.

I passed at the third test.

The results are as follows:-

I35 have been discharged, after being kept under observation for 6 to 12 months following the termination of the test.

Of these, one has been re-admitted for further treatment, a lepromatous case. 85 are still under observation, but not under treatment. I4 remain under treatment with Moogrol, still show active signs, neural cases, negative to microscope. 4 died from intercurrent diseases. 3 remain for economic reasons, disease arrested. 3 are still undergoing test.

Now, we have to consider 34 cases, who were still positive (ear or nose or both) though showing no active signs of the disease.

Of these 34 cases, 25 passed the test, and 9 failed, I5 of them remain under observation, apparently " arrested " cases, whilst 7 have required further treatment, active signs having supervened, and $\mathrm{I} 2$ have been discharged provisionally. These cases are of special interest.

The question is raised, is Pot. Iodide a test at all? 25 cases out of 34 , who were still positive, and who were not considered as fit for discharge, passed the test. In these cases, the test was far from reliable. Had these cases been discharged, I feel quite sure that a large proportion of them ivould have returned for further treatment sooner or later. The 12 cases who were discharged were carefully chosen as being the least likely to recur, and it will be interesting to follow up their future history.

The test should be applied only to these cases who are in good physical condition, and who clinically appear fit for discharge. Caution must be exercised before discharging symptom-free cases who are still slightly positive, even though they have passed the test. Each case must be considered on its merits, but I do not think it is necessary to continue treatment in all positive cases until they become negative, and remain so for some months. A risk must be taken occasionally.

The test is not infallible, but it is distinctively useful, and has become routine practice at this hospital. 